\title{
Corrigendum: Conjugative Transfer of a Novel Staphylococcal Plasmid Encoding the Biocide Resistance Gene, qacA
}

\author{
Patrick T. LaBreck', Gregory K. Rice ${ }^{2,3}$, Adrian C. Paskey ${ }^{1,2}$, Emad M. Elassal4,5, \\ Regina Z. Cer ${ }^{2,3}$, Natasha N. Law ${ }^{4,5,6}$, Carey D. Schlett ${ }^{4,5}$, Jason W. Bennett ${ }^{7,8}$, \\ Eugene V. Millar ${ }^{4,5}$, Michael W. Ellis ${ }^{9}$, Theron Hamilton ${ }^{2}$, Kimberly A. Bishop-Lilly ${ }^{2}$ and \\ D. Scott Merre/l ${ }^{1,8 *}$
}

${ }^{1}$ Department of Microbiology and Immunology, Uniformed Services University of the Health Sciences, Bethesda, MD, United States, ${ }^{2}$ Naval Medical Research Center, Biological Defense Research Directorate, Fort Detrick, MD, United States, ${ }^{3}$ Leidos, Reston, VA, United States, ${ }^{4}$ Henry M. Jackson Foundation for the Advancement of Military Medicine, Rockville, MD, United States, ${ }^{5}$ Infectious Diseases Clinical Research Program, Department of Preventive Medicine and Biostatistics, Uniformed Services University of the Health Sciences, Bethesda, MD, United States, ${ }^{6}$ Martin Army Community Hospital, Fort Benning, GA, United States, ${ }^{7}$ Walter Reed Army Institute of Research, Silver Spring, MD, United States, ${ }^{8}$ Department of Medicine, Uniformed Services University of the Health Sciences, Bethesda, MD, United States, ${ }^{9}$ University of Toledo College of Medicine and Life Sciences, Toledo, OH, United States

Keywords: antiseptic, Chlorhexidine digluconate, Staphylococcus aureus, plasmid acquisition, conjugation

\section{A Corrigendum on}

Edited and reviewed by: Katy Jeannot, UMR6249 Chrono

Environnement, France

*Correspondence:

D. Scott Merrell

douglas.merrel/@usuhs.edu

Specialty section:

This article was submitted to Antimicrobials, Resistance and Chemotherapy,

a section of the journal Frontiers in Microbiology

Received: 10 January 2020 Accepted: 15 April 2020 Published: 14 May 2020

Citation:

LaBreck PT, Rice GK, Paskey AC, Elassal EM, Cer RZ, Law NN, Schlett CD, Bennett JW, Millar EV, Ellis MW, Hamilton T, Bishop-Lilly KA and Merrell DS (2020) Corrigendum:

Conjugative Transfer of a Novel

Staphylococcal Plasmid Encoding the

Biocide Resistance Gene, qacA.

Front. Microbiol. 11:877.

doi: 10.3389/fmicb.2020.00877
Conjugative Transfer of a Novel Staphylococcal Plasmid Encoding the Biocide Resistance Gene, qacA

by LaBreck, P. T., Rice, G. K., Paskey, A. C., Elassal, E. M., Cer, R. Z., Law, N. N., et al. (2018). Front. Microbiol. 9:2664. doi: 10.3389/fmicb.2018.02664

The authors wish to correct an improper bacterial species designation in the original article. Post publication, whole genome sequencing and targeted $r p o B$ sequencing revealed that "S. epidermidis RN and S. epidermidis RN TC" are actually Staphylococcus capitis. Thus, all utilizations of "S. epidermidis RN and S. epidermidis RN TC" in the article should be replaced with "S. capitis RN" and "S. capitis RN TC", respectively.

Additionally, a correction has been made to Keywords, (specific changes are underlined):

Staphycoccus aureus was changed to Staphylococcus aureus due to a misspelling.

A correction has been made to Keywords, (specific changes are underlined):

Chlorhexedine digluconate was changed to Chlorhexidine digluconate due to a misspelling.

A correction has been made to Introduction, Paragraph Number 5 (specific changes are underlined). In the original edited stage, a sentence was incorrectly pasted into the introduction. This sentence should be removed and has a strikethrough to designate the deletion.

Various studies have sought to understand the ability of individual Qac efflux pumps to mediate decreased susceptibility to antiseptics. For example, the QacA efflux pump has been shown to confer protection against quaternary ammonium compounds and to divalent organic cations like chlorhexidine. Conversely, while QacB is highly similar to QacA and is also part of the same major facilitator superfamily (MFS), QacB appears to offer little/no protection to divalent organic cations (Paulsen et al., 1996). The other Qac efflux pumps (QacC-QacJ and QacZ) are part of the Small Multidrug Transporter (SMR) family and each have various effects on antiseptic resistance (Furi et al., 2013; Wassenaar et al., 2015). The genes encoding the Qac efflux pumps are located 
on plasmids, which impacts possible mechanisms of spread of these genes across strains. For example, qacC, which is also known as smr, was previously found to be carried on conjugative plasmids as well as on small rolling circle plasmids (Littlejohn et al., 1991; Morton et al., 1993; Berg et al., 1998). Furthermore, transduction has been shown to facilitate transfer of plasmid-born $q a c B$ across strains. The corrected sentence should read. Conversely, qacA has only been found on large non-conjugative multidrug resistance plasmids; these plasmids lack the transfer, or tra genes, that are required

\section{REFERENCES}

Berg, T., Firth, N., Apisiridej, S., Hettiaratchi, A., Leelaporn, A., and Skurray, R. A. (1998). Complete nucleotide sequence of pSK41: evolution of staphylococcal conjugative multiresistance plasmids. J. Bacteriol. 180, 4350-4359.

Furi, L., Ciusa, M. L., Knight, D., Di Lorenzo, V., Tocci, N., Cirasola, D., et al. (2013). Evaluation of reduced susceptibility to quaternary ammonium compounds and bisbiguanides in clinical isolates and laboratory-generated mutants of Staphylococcus aureus. Antimicrob. Agents Chemother. 57, 3488-3497. doi: 10.1128/AAC.00498-13

Littlejohn, T. G., DiBerardino, D., Messerotti, L. J., Spiers, S. J., and Skurray, R. A. (1991). Structure and evolution of a family of genes encoding antiseptic and disinfectant resistance in Staphylococcus aureus. Gene 101, 59-66. doi: 10.1016/0378-1119(91)90224-Y

McCarthy, A. J., and Lindsay, J. A. (2012). The distribution of plasmids that carry virulence and resistance genes in Staphylococcus aureus is lineage associated. BMC Microbiol. 12:104. doi: 10.1186/1471-2180-12-104

Morton, T., Eaton, D., Johnston, J., and Archer, G. (1993). DNA sequence and units of transcription of the conjugative transfer gene complex (trs) of Staphylococcus aureus plasmid pGO1. J. Bacteriol. 175, 4436-4447. doi: 10.1128/jb.175.14.4436-4447.1993

Nakaminami, H., Noguchi, N., Nishijima, S., Kurokawa, I., So, H., and Sasatsu, M. (2007). Transduction of the plasmid encoding antiseptic resistance for conjugative transfer (Tennent et al., 1989; McCarthy and Lindsay, 2012). As a result, horizontal transfer of qacA has not previously been documented (Nakaminami et al., 2007). Thus, it is not clear how or whether qacA is able to be horizontally spread across $S$. aureus strains, and if so, whether such spread could contribute to the prevalence of this factor in the S. aureus population.

The authors apologize for this error and state that this does not change the scientific conclusions of the article in any way. The original article has been updated.

gene qacB in Staphylococcus aureus. Biol. Pharmaceut. Bull. 30, 1412-1415. doi: $10.1248 / \mathrm{bpb} .30 .1412$

Paulsen, I. T., Brown, M. H., Littlejohn, T. G., Mitchell, B. A., and Skurray, R. A. (1996). Multidrug resistance proteins QacA and QacB from Staphylococcus aureus: membrane topology and identification of residues involved in substrate specificity. Proc. Natl. Acad. Sci. U.S.A. 93, 3630-3635. doi: 10.1073/pnas.93. 8.3630

Tennent, J. M., Lyon, B. R., Midgley, M., Jones, G., Purewal, A. S., and Skurray, R. A. (1989). Physical and biochemical characterization of the qacA gene encoding antiseptic and disinfectant resistance in Staphylococcus aureus. J. Gen. Microbiol. 135, 1-10.

Wassenaar, T. M., Ussery, D., Nielsen, L. N., and Ingmer, H. (2015). Review and phylogenetic analysis of qac genes that reduce susceptibility to quaternary ammonium compounds in Staphylococcus species. Eur. J. Microbiol. Immunol. 5, 44-61. doi: 10.1556/EuJMI-D-14-00038

Copyright (C) 2020 LaBreck, Rice, Paskey, Elassal, Cer, Law, Schlett, Bennett, Millar, Ellis, Hamilton, Bishop-Lilly and Merrell. This is an open-access article distributed under the terms of the Creative Commons Attribution License (CC BY). The use, distribution or reproduction in other forums is permitted, provided the original author(s) and the copyright owner(s) are credited and that the original publication in this journal is cited, in accordance with accepted academic practice. No use, distribution or reproduction is permitted which does not comply with these terms. 